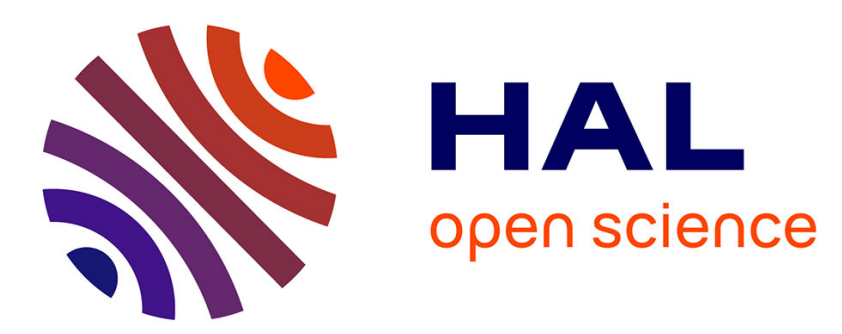

\title{
Risk Management Plans: are they a tool for improving drug safety?
}

Serena Frau, Maria Font Pous, Maria Rosa Luppino, Anita Conforti

\section{To cite this version:}

Serena Frau, Maria Font Pous, Maria Rosa Luppino, Anita Conforti. Risk Management Plans: are they a tool for improving drug safety?. European Journal of Clinical Pharmacology, 2010, 66 (8), pp.785-790. 10.1007/s00228-010-0848-8 . hal-00603445

\section{HAL Id: hal-00603445 https://hal.science/hal-00603445}

Submitted on 25 Jun 2011

HAL is a multi-disciplinary open access archive for the deposit and dissemination of scientific research documents, whether they are published or not. The documents may come from teaching and research institutions in France or abroad, or from public or private research centers.
L'archive ouverte pluridisciplinaire HAL, est destinée au dépôt et à la diffusion de documents scientifiques de niveau recherche, publiés ou non, émanant des établissements d'enseignement et de recherche français ou étrangers, des laboratoires publics ou privés. 


\title{
Risk Management Plans: are they a tool for improving drug safety?
}

\author{
Serena Frau • Maria Font Pous • Maria Rosa Luppino • \\ Anita Conforti
}

Received: 18 March 2010 /Accepted: 20 May 2010 /Published online: 25 June 2010

(C) Springer-Verlag 2010

\begin{abstract}
Purpose In 2005, new European legislation authorised Regulatory Agencies to require drug companies to submit a risk management plan (RMP) comprising detailed commitments for post-marketing pharmacovigilance. The aim of the study is to describe the characteristics of RMP for 15 drugs approved by the European Medicines Agency (EMA) and their impact on post-marketing safety issues. Methods Of the 90 new Chemical Entities approved through a centralised procedure by the EMA during 2006 and 2007, 15 of them were selected and their safety aspects and relative RMPs analysed. All post-marketing communications released for safety reasons related to these drugs were also considered.

Results A total of 157 safety specifications were established for the drugs assessed. Risk minimisation activities were
\end{abstract}

\section{S. Frau}

Dialogo sui Farmaci, Pharmaceutical Department,

Verona Local Health Unit,

Verona, Italy

M. Font Pous

Pharmaceutical Department, Verona Local Health Unit,

Verona, Italy

\section{R. Luppino}

Department of Clinical and Experimental Medicine and Pharmacology, Pharmacology Unit, University of Messina,

Messina, Italy

\author{
A. Conforti \\ Clinical Pharmacology Unit, University of Verona, \\ Verona, Italy \\ M. Font Pous $(\bowtie)$ \\ Dialogo sui Farmaci, Pharmaceutical Department, \\ Verona Local Health Unit, \\ Via Salvo d'Acquisto 7, \\ 37122 Verona, Italy \\ e-mail: maria.font@ulss20.verona.it
}

foreseen for 5 drugs as training activities. Post-marketing safety issues emerged for 12 of them, leading to 39 type II variations in Summary of Product Characteristics (SPC). Nearly half of such variations, 19 (49\%), concerned safety aspects not envisaged by the RMPs. Besides this, 9 Safety Communications were published for 6 out of 15 drugs assessed.

Conclusion The present study reveals several critical points on the way RMPs have been implemented. Several activities proposed by the RMPs do not appear to be adequate in dealing with the potential risks of drugs. Poor communication of risk to practitioners and to the public, and above all limited transparency for the total assessment of risk, seem to transform RMPs into a tool to reassure the public when inadequately evaluated drugs are granted premature marketing authorisation.

Keywords Risk management · Risk assessment $\cdot$ Safety management S Surveillance programs · Hazard ·

Postmarketing product surveillance

\section{Background}

Repeated incidents on drug safety have highlighted the weaknesses of the European pharmacovigilance system, relying mainly on the spontaneous reporting of adverse drug events. Stricter assessment before drug approval and more intensive post-marketing surveillance through alternative tools like randomised clinical trials, observational studies and use of registries could have prevented or limited such incidents [1, 2]. From 2005, new European legislation has authorised regulatory agencies to require drug companies to submit, along with their application for marketing authorisation, a risk management plan comprising detailed commitments to post-marketing pharmacovigilance [1].

A product Risk Management Plan (RMP) is defined as a plan identifying the risks associated with a medicinal 
product, methods of further clarifying the safety profile of a product, and tools designed to minimise the risk to individual patients in clinical practice [3]. Since the implementation of RMPs in Europe, only one publication has critically assessed their role in improving the safety of marketed drugs [4].

The following paper is based on the risk/benefit assessment of new drugs marketed in Italy carried out by the drug information bulletin Dialogo sui Farmaci, a member of the International Society of Drug Bulletins (ISDB). The aim of the study is to describe the characteristics of RMPs for 15 drugs approved by the European Medicines Agency (EMA), and their impact on post-marketing safety issues.

\section{Materials and methods}

Among 90 drugs approved by the Committee for Medicinal Products for Human Use (CHMP) of the EMA between 2006 and 2007, we selected those that were marketed in Italy in 2007 and 2008 (i.e. 38 products). From these, we excluded orphan drugs (11), new associations (4), newly labelled indications (2), drugs for topical use (1) and 5 drugs that were not assessed by Dialogo sui Farmaci.

The remaining 15 drugs belong to the following therapeutic categories:

1. Drugs for the prevention of different risk factors:

a) Antidiabetics: exenatide, vildagliptin, sitagliptin

b) Smoking cessation: varenicline

c) Antiobesity: rimonabant

2. Vaccines: tetravalent and bivalent HPV vaccine; Rotavirus vaccine

3. Anti-infective drugs: anidulafungin, entecavir, telbivudine

4. Biological drugs: abatacept; ranibizumab; methoxy polyethylene glycol epoetin beta (MPEG epoetin beta)

5. Others: paliperidone

The safety data available in the public domain of the European Public Assessment Report (EPAR) for these 15 drugs have been analysed and compared with the information contained in the summary of the Risk Management Plan published in the same document (EPAR) [5]. The structure of a Risk Management Plan and the different sections of each part are described in Table 1.

In order to verify if the studies required in the RMP were ongoing or not, we consulted two databases of clinical studies registries (clinicaltrial.gov and the WHO register) up to June 2009, using the ID number of clinical studies reported in RMP, when available. With regard to the postmarketing changes published for safety reasons up to June 2009, we checked all type II modifications (major changes) contained in the Summary of Product Characteristics (SPC) introduced for safety reasons. These changes are available in the document "Steps taken after authorisation" of the EPAR. Moreover, we examined all the safety communications published by the EMA (like press releases or public statements) about the selected drugs [6].

\section{Results}

What did RMPs address?

While a total of 157 safety specifications had been determined for the 15 drugs assessed, the type of risk (defined as identified risk, potential risk or important missing information) was detailed for just 7 of them. Common activities included for all the 15 drugs were routine pharmacovigilance and SPC modifications. Additional Pharmacovigilance Activities (experimental or observational studies) and Additional Risk Minimisation Activities proposed for each drug are shown in Table 2. No additional pharmacovigilance activities (i.e. new safety studies) were found for two drugs: paliperidone and sitagliptin. Among the studies required for 13 drugs, many were not described or were not identifiable through an ID number: in fact only 5 of them were found in the clinical trial registries at least 2 years after approval of the drugs, as shown in Table 3. For 5 drugs, risk minimisation activities in the form of training activities were included for practitioners (3), for patients (1) or for both (1).

\section{Post-marketing safety measures}

After these drugs were marketed and up to June 2009, safety issues had emerged for 12 of them, leading to 39 type II variations in SPC, including new adverse effects, contraindications, warnings, interactions or other safetyrelated information. Nearly half of such variations, i.e. 19 $(49 \%)$ of them, regarded new safety concerns not previously considered by the RMPs. Among the remaining 20 variations (51\%), only 1 (entecavir and the risk of HVB virus resistance) resulted from a study reported in the RMP; 13 of these emerged from post-marketing studies not mentioned in the RMP (i.e. telbivudine and peripheral neuropathy, for which the RMP proposed only routine pharmacovigilance. This adverse effect motivated the publication of a public statement. Rotavirus vaccine and apnoea in premature infants and entecavir and HIV resistance were safety concerns not envisaged in their RMP). Finally, 6 modifications were due to routine pharmacovigilance.

In addition, 9 Safety Communications (SC: press releases or public statements) had been published for 6 out of 15 drugs assessed (Table 3). 
Table 1 Structure of a Risk Management Plan (RMP)

\begin{tabular}{|c|c|c|c|c|}
\hline & \multicolumn{2}{|l|}{ Part II } \\
\hline \multirow[t]{2}{*}{ Safety specification } & \multicolumn{2}{|l|}{ Pharmacovigilance plan } & \multicolumn{2}{|l|}{ Risk minimisation plan } \\
\hline & Routine pharmacovigilance & $\begin{array}{l}\text { Additional } \\
\text { pharmacovigilance } \\
\text { activities }\end{array}$ & $\begin{array}{l}\text { Routine risk minimisation } \\
\text { activities }\end{array}$ & $\begin{array}{l}\text { Additional risk } \\
\text { minimisation activities }\end{array}$ \\
\hline $\begin{array}{l}\text { Safety specification } \\
\text { concerns three type of } \\
\text { risks: identified risk } \\
\text { (adverse effects [AE] } \\
\text { observed in clinical trials } \\
\text { or epidemiological studies } \\
\text { for which the magnitude } \\
\text { of the difference, } \\
\text { compared with the } \\
\text { comparator group, on a } \\
\text { parameter of interest } \\
\text { suggests a causal } \\
\text { relationship); potential } \\
\text { risk (AE observed only in } \\
\text { pre-clinical trials; in } \\
\text { clinical trials but with a } \\
\text { low incidence rate and } \\
\text { without a casual } \\
\text { relationship; an event that } \\
\text { is known to be associated } \\
\text { with other products of the } \\
\text { same class); important } \\
\text { missing information } \\
\text { (information that is not } \\
\text { available at the time of } \\
\text { submission and that } \\
\text { represents a limitation of } \\
\text { the safety data with } \\
\text { respect to predicting the } \\
\text { safety of the product in } \\
\text { the marketplace). }\end{array}$ & $\begin{array}{l}\text { Pharmacovigilance } \\
\text { activities: report of } \\
\text { suspected adverse } \\
\text { reactions by doctors and } \\
\text { other health care } \\
\text { professionals to the } \\
\text { competent authorities; } \\
\text { Periodic Safety Update } \\
\text { Report (PSUR) }\end{array}$ & $\begin{array}{l}\text { For medicinal products } \\
\text { with significant identified } \\
\text { risks, significant potential } \\
\text { risks or significant } \\
\text { missing information, } \\
\text { activities designed to } \\
\text { address these safety } \\
\text { concerns should be } \\
\text { considered, e.g. new } \\
\text { post-marketing studies, } \\
\text { monitoring ongoing } \\
\text { studies, use of registries. }\end{array}$ & $\begin{array}{l}\text { The warnings and } \\
\text { information contained } \\
\text { within the Summary of } \\
\text { Product Characteristics } \\
\text { and the Patient Leaflet, } \\
\text { and the careful use of } \\
\text { labelling and packaging, } \\
\text { which aim to reduce the } \\
\text { probability of an adverse } \\
\text { reaction occurring or its } \\
\text { severity. }\end{array}$ & $\begin{array}{l}\text { Activities in which a } \\
\text { reduction in risk is } \\
\text { achieved primarily } \\
\text { through the provision } \\
\text { of information and } \\
\text { education (e.g. } \\
\text { educational material or } \\
\text { training programmes for } \\
\text { prescribers, pharmacists } \\
\text { and patients) or activities } \\
\text { seeking to control the } \\
\text { use of the medicine } \\
\text { (e.g. restricted medical } \\
\text { prescription, restricted } \\
\text { access programmes). }\end{array}$ \\
\hline
\end{tabular}

Two SCs reported events not previously included in the related RMPs of two drugs (two cases of death in subjects vaccinated with the tetravalent HPV vaccine, events not considered as causally related to the vaccine; entecavir and HIV-resistant strains in 3 patients with HIV co-infection).

Two further SCs concerned the risk of epoetins in patients with chronic kidney disease, which may be associated with an increased risk of mortality and cardiovascular morbidity. The RMP included a post-marketing safety study for thromboembolic events.

The remaining 5 SCs related to three drugs and reported safety concerns already included in the RMPs. Telvibudine was associated with peripheral neuropathy, varenicline with suicidal ideation and suicide attempts, and 3 SCs were issued for rimonabant. As regards rimonabant, the first SC contraindicated its use in patients with ongoing major depression or those treated with antidepressants and the other 2 SCs announced its suspension and subsequent withdrawal because of serious psychiatric events.

Pharmacovigilance activities foreseen in the RMPs of these three drugs were mainly routine pharmacovigilance. For rimonabant, an unspecified study was also included; the intensification of the psychiatric events described in the SC, however, was mainly based on case reports and cumulative reviews. No safety data emerged for 3 out of the 15 drugs assessed (anidulafungin, abatacept, bivalent HPV vaccine).

\section{Discussion}

How can RMPs improve pharmacovigilance?

In order to "reinforce" routine pharmacovigilance, RMPs have included additional pharmacovigilance activities that go beyond spontaneous reports, such as new specific 
Table 2 Main features of the RMPs of the 15 drugs

\begin{tabular}{|c|c|c|c|c|c|}
\hline Drug & Therapeutic indication & $\begin{array}{l}\text { Number } \\
\text { of RMP } \\
\text { safety } \\
\text { concerns }\end{array}$ & Required new studies in the RMP & $\begin{array}{l}\text { Additional risk } \\
\text { minimisation } \\
\text { activities }\end{array}$ & $\begin{array}{l}\text { Identification } \\
\text { of type of } \\
\text { risk }^{\mathrm{a}}\end{array}$ \\
\hline Exenatide & Type II diabetes & 10 & $\begin{array}{l}4 \text { clinical trials; meta-analyses from } \\
\text { long-term studies in } 2007 \text { and } 2009 \text {; } \\
1 \text { database study }\end{array}$ & No & No \\
\hline Sitagliptin & Type II diabetes & 10 & No & No & Yes \\
\hline Vildagliptin & Type II diabetes & 14 & $\begin{array}{l}\text { Total number of studies not specified: } \\
\text { post-marketing epidemiological study; } \\
\text { cohort observational study; clinical studies }\end{array}$ & No & No \\
\hline Varenicline & Smoking cessation & 8 & $\begin{array}{l}5 \text { randomised clinical trials }+1 \\
\text { observational study }\end{array}$ & No & Yes \\
\hline Rimonabant & Obesity & 16 & $\begin{array}{l}\text { Total number of studies not specified. } \\
2 \text { observational studies, } 1 \text { disease registry. } \\
\text { Monitoring prescription }\end{array}$ & For practitioners & Yes \\
\hline $\begin{array}{l}\text { Tetravalent } \\
\text { HPV } \\
\text { vaccine }\end{array}$ & $\begin{array}{l}\text { Prevention of pre-malignant } \\
\text { genital lesions, cervical } \\
\text { cancer and external genital } \\
\text { warts related to HPV }\end{array}$ & 4 & $\begin{array}{l}\text { Pregnancy registry; post-marketing safety } \\
\text { study; Norwegian vaccine study, Nordic } \\
\text { Cancer registry, adolescent cohort study } \\
\text { and adolescent extension study }\end{array}$ & No & No \\
\hline $\begin{array}{l}\text { Bivalent HPV } \\
\text { vaccine }\end{array}$ & $\begin{array}{l}\text { Prevention of pre-malignant } \\
\text { cervical lesions and cervical } \\
\text { cancer causally related to HPV }\end{array}$ & 7 & $\begin{array}{l}4 \text { ongoing studies; } 7 \text { clinical trials; } \\
1 \text { cohort study; } 1 \text { pregnancy register }\end{array}$ & No & Yes \\
\hline $\begin{array}{l}\text { Rotavirus } \\
\text { vaccine }\end{array}$ & Rotavirus immunisation & 7 & $\begin{array}{l}\text { Post-marketing safety surveillance study; } \\
1 \text { clinical trial }\end{array}$ & No & No \\
\hline Anidulafungin & Invasive candidiasis & 10 & 3 clinical trials +2 observational studies & No & Yes \\
\hline Telbivudine & HVB & 9 & $\begin{array}{l}\text { Ongoing and planned future studies } \\
\text { (not identified) }\end{array}$ & For practitioners & Yes \\
\hline Entecavir & HVB & 7 & $\begin{array}{l}4 \text { new studies not specified; roll-over } \\
\text { studies and large observational study; } \\
\text { ongoing studies (not identified) }\end{array}$ & No & No \\
\hline Abatacept & Rheumatoid arthritis & 11 & $\begin{array}{l}2 \text { new studies not specified, } 5 \\
\text { epidemiological studies; } 2 \text { registries }\end{array}$ & For patients & Yes \\
\hline $\begin{array}{l}\text { MPEG } \\
\text { epoetin beta }\end{array}$ & $\begin{array}{l}\text { Anaemia associated with } \\
\text { CKD }\end{array}$ & 10 & Paediatric development programme & For practitioners & No \\
\hline Ranibizumab & $\begin{array}{l}\text { Age-related macular } \\
\text { degeneration }\end{array}$ & 6 & 3 observational studies & $\begin{array}{l}\text { For patients and } \\
\text { practitioners }\end{array}$ & No \\
\hline Paliperidone & Schizophrenia & 28 & No & No & No \\
\hline
\end{tabular}

HPV, human papilloma virus; MPEG, methoxy polyethylene glycol ; HVB, hepatitis B virus; CKD, chronic kidney disease

${ }^{a}$ Identification of type of risk: in the Safety Specification section of each RMP, the type of risk surveyed should be classified as identified risk, potential risk or important missing information

studies planned for safety reasons including observational ones, or monitoring safety aspects of ongoing clinical trials. These activities could provide stronger and more timely evidence on safety and speed up procedural steps for adequate measures to be taken.

Among the Risk Minimisation Activities, information and training activities for practitioners and patients are new tools, different from SPC modifications, which could, at least theoretically, help to improve risk communication and consequently minimise harm caused by new drugs.

The real value of RMPs as a tool to identify, clarify and minimise risks can be estimated by comparing the clinical safety of each drug with the safety concerns considered and developed in the RMP (both available in the scientific discussion of the EPAR) at the time of drug approval. A second step compares the activities foreseen in the RMP (mainly additional pharmacovigilance activities and a risk minimisation plan) with the safety aspects that emerged in the post-marketing phase (SPC type II modifications for safety reasons and EMA safety communications). This analysis reveals several critical points about the way RMPs have been implemented and about their real value.

Several activities proposed by the RMPs do not appear to be adequate for dealing with the potential risks of drugs

Pharmacovigilance activities foreseen in the RMP to address safety concerns appear inadequate for ascertaining the observed risks. Rimonabant is one such example, where psychiatric side effects, depression in particular, were 
Table 3 Main safety changes after drug approval for the 15 drugs

\begin{tabular}{|c|c|c|c|}
\hline Drug & $\begin{array}{l}\text { Studies found } \\
\text { in clinical } \\
\text { trials } \\
\text { registries }\end{array}$ & $\begin{array}{l}\text { SPC Type II } \\
\text { safety } \\
\text { modifications }\end{array}$ & $\begin{array}{l}\text { EMA Safety } \\
\text { Communication: } \\
\text { public statement } \\
\text { or press release }\end{array}$ \\
\hline Exenatide & Yes & 3 & No \\
\hline Sitagliptin & No & 3 & No \\
\hline Vildagliptin & No & 2 & No \\
\hline Varenicline & Yes & 6 & $14 / 12 / 2007$ \\
\hline Rimonabant & No & 3 & $\begin{array}{l}19 / 07 / 2007 \\
23 / 10 / 2008^{\mathrm{a}} \\
30 / 01 / 2009^{\mathrm{a}}\end{array}$ \\
\hline $\begin{array}{l}\text { Tetravalent } \\
\text { HPV vaccine }\end{array}$ & No & 4 & $24 / 01 / 2008$ \\
\hline $\begin{array}{l}\text { Bivalent HPV } \\
\text { vaccine }\end{array}$ & No & 0 & No \\
\hline $\begin{array}{l}\text { Rotavirus } \\
\text { vaccine }\end{array}$ & No & 6 & No \\
\hline Anidulafungin & Yes & 0 & No \\
\hline Entecavir & Yes & 5 & 05/03/2007 \\
\hline Telbivudine & No & 2 & $14 / 02 / 2008$ \\
\hline Abatacept & Yes & 0 & No \\
\hline Ranibizumab & No & 2 & No \\
\hline $\begin{array}{l}\text { MPEG } \\
\text { epoetin beta }\end{array}$ & No & 2 & $\begin{array}{l}27 / 4 / 2007 \\
23 / 10 / 2007\end{array}$ \\
\hline Paliperidone & No & 1 & No \\
\hline
\end{tabular}

SPC, Summary of Product Characteristics; EMA, European Medicines Agency

${ }^{\mathrm{a}}$ Suspended and withdrawn

already identified as the main safety issues at the time of approval. The proposed activities considered in the RMP, among them an unspecified study, and further changes in the SPC, were inadequate for minimising a risk that caused its withdrawal 2 years later.

Another example is varenicline: its RMP identified as safety concerns "adverse events associated with smoking cessation (which included depressed mood, insomnia, irritability/frustration/anger, restlessness, and concentration difficulties)", stating that "no attempt was made in the analysis of varenicline safety data to distinguish between the events associated with varenicline and those associated with nicotine withdrawal". For this safety issue, only routine pharmacovigilance was proposed. Three years after the launch of varenicline, 4 out of 6 SPC modifications were due to psychiatric events.

Cardiac events such as increased incidence of atriumventricular block were observed with vildagliptin in both animal models and clinical studies. Although the EMA recommended that specific post-marketing studies on cardiovascular safety should be conducted, the approved RMP did not include any study to monitor heart-related adverse effects, but simply suggested routine pharmacovigilance activities.

\section{Poor risk communication}

Providing risk-related information is a crucial step: if safety information fails to reach health professionals and patients within adequate timeframes, the whole RMP system and pharmacovigilance itself will lose significance. The criteria whereby some pieces of information are addressed through SPCs change while others are the subject of public statements are unclear. The following examples illustrate the case.

At the time of exenatide approval, 40 cases of pancreatitis were observed, which progressively increased in number. Pancreatitis as well as acute renal damage are included as rare events in the SPC update, although no quantitative data are supplied. An SC might be more adequate for serious reactions such as these. Other Regulatory Agencies, such as the FDA in the USA or the MHRA (Medicines Healthcare products Regulatory Agency) in the UK, have published official communications through "Dear Healthcare Professional" letters or pharmacovigilance newsletters about such risks $[7,8]$.

Another example is rimonabant. Warnings such as the one against administering rimonabant to individuals with pre-existing depression or who are using antidepressants should have been issued as contraindications earlier; the same applies to epileptic patients. Repeated changes in warnings in the SPC do not seem to protect patients adequately.

\section{Limited transparency}

A major issue, which is also the main limitation of this study, is the lack of publically available data regarding the most significant aspects of the RMPs. Information is particularly lacking in the area of additional pharmacovigilance activities. The article by Giezen et al. [4] assessed the RMP of 18 drugs ( 8 of them are the same as those analysed in this article). Having access to the study protocols foreseen in the RMP, the authors report that no one study had a complete protocol, $26 \%$ submitted a limited protocol, the remaining $74 \%$ had a study synopsis, a short description or just a commitment to perform a study. The educational programmes for doctors and patients are also lacking in any content. There is thus a tangible risk that these programmes could become a promotional tool instead of improving the safe use of drugs.

Other important data such as whether the drug has been submitted or not to the EMA regulatory authorities for scientific advice or protocol assistance in the evaluation process, before drug approval, are also lacking. According 
to Giezen et al., marketing authorisation applicants and regulators should have active discussions on postmarketing studies early in the evaluation process by way of scientific advice. However, major involvement of regulators in drug development, through scientific advice, could make CHMP decisions binding, thus making drug assessment less independent [9]. Minimal conditions for effective transparency on RMPs implies publically available data about the proposed pharmacovigilance activities, particularly full study protocols and clear timelines for their development, as well as more information on doctor and patient programmes.

New directions in European pharmacovigilance

The proposed Regulation and Directive of December 2008 concerning pharmacovigilance proposes, among many other measures, more widespread use of risk management systems, particularly if there are concerns about risks "affecting the risk-benefit balance of an authorised product and which should be proportioned to the risks" [10-12]. According to the proposal, if concerns exist about the safety of a drug authorised for exceptional circumstances, a marketing authorisation can be granted provided that postauthorisation studies are conducted. However, as this report and a few other publications show, a large proportion of the studies required after drug approval are being conducted too late or simply not being carried out at all [13]. The trend observed in recent years by the EMA, showing that many drug safety aspects that have not been duly clarified at the time of approval are being shifted to the post-marketing phase, does not appear to be adequately manageable through RMPs and consequently poses a danger to patients. Instead, more stringent pre-marketing evaluation should be required. Several other measures proposed in the new Regulation and Directive will weaken rather than strengthen the European Pharmacovigilance system, for instance, the creation of a Pharmacovigilance Risk Assessment Advisory Committee (PRAAC), not independent from the CHMP, which will continue to have the final responsibility for the risk-benefit assessment of medicinal products (article 9). Moreover, pharmacovigilance activities would be funded through the collection of fees charged to marketing authorisation holders (article 11) [11].

\section{Conclusions}

It seems too early to give a comprehensive assessment of RMP effectiveness as a pharmacovigilance tool, particularly based on the limited number of drugs assessed. RMPs, as they are implemented, are at risk of being another "cosmetic" intervention, with no real impact on the improvement of drug safety for European citizens.

Risk Management Plans could bring added value to pharmacovigilance provided that the main safety concerns are not deferred until the post-marketing phase, that additional pharmacovigilance activities are adequate for the proposed safety concerns and that post-marketing studies become mandatory for marketing authorisation holders. Besides this, greater transparency by the EMA in providing safety information for the public and for health professionals is now an absolute requirement $[2,9,14]$.

Acknowledgements Maria Font Pous (MFP) is an expert on drug information and former President of the International Society of Drug Bulletins (ISDB). Serena Frau (SF) is member of the editorial board of an independent drug bulletin that regularly assesses drugs. MFP and SF have designed the study and developed part of the analysis. Anita Conforti (AC) is an expert in pharmacovigilance in the Veneto Region and a reviewer for the WHO collaborating Center for International Drug Monitoring Center (Uppsala). Maria Rosa Luppino (MRL) is an expert in pharmacovigilance and drug information. AC and MRL developed part of the data analysis. All the authors have reviewed and approved the final draft. MFP is the guarantor.

Conflicts of interest None.

\section{References}

1. Eichler HG, Abadie E, Raine J, Salmonson T (2009) Safe drugs and the cost of good intentions. N Engl J Med 360:1378-1380

2. Garattini S, Chalmers I (2009) Patients and the public deserve big changes in evaluation of drugs. BMJ 338:804-807

3. EudraLex, vol 9A. Pharmacovigilance guidelines. http://ec.europa.eu/ enterprise/pharmaceuticals/eudralex/vol9_en.htm. Accessed 26 May 2009

4. Giezen TJ, Mantel-Teeuwisse AK, Straus SMJM, Egberts TCG, Blauckburn S et al (2009) Evaluation of post-authorization safety studies in the first cohort of EU Risk Management Plans at time of regulatory approval. Drug Saf 32:1175-1187

5. EPARs for authorised medicinal products for human use. www. emea.europa.eu/htms/human/epar/a.htm

6. Human Medicines Product Safety Announcements. www.emea. europa.eu/htms/human/drugalert/drugalert.htm

7. MHRA-CHM (2009) Exenatide (Byetta): risk of severe pancreatitis and renal failure. MHRA Drug Saf Update 8:6-7

8. Byetta (exenatide) (2008) FDA Drug Safety Newsletter 2:12-14 www.fda.gov/medwatch/safety/2007/

9. Garattini S, Bertelé V (2010) Europe's opportunity to open up drug regulation. BMJ 340:842-843

10. Proposed Directive: http://eurlex.europa.eu/LexUriServ/LexUriServ. do?uri=COM:2008:0665:FIN:EN:PDF

11. Proposed Regulation: http://eurlex.europa.eu/LexUriServ/LexUriServ. do?uri=COM:2008:0664:FIN:EN:PDF

12. EU Commission's proposals on pharmacovigilance dismantle the entire system (2009) Joint position of AIM, ESIP, HAI Europe, ISDB, MiEF. Available at www.isdbweb.org/

13. Avorn J (2007) Paying for drug approvals. Who's using whom? N Engl J Med 356:1697-1700

14. Garattini S, Bertele V (2007) How can we regulate medicines better? BMJ 335:803-805 